\title{
Comparison of two cone beam computed tomography multiplanar reconstruction orientation protocols
}

\author{
Vandana Kumar' ${ }^{1}$, Dan Ang ${ }^{2}$, Karen Williams ${ }^{3}$, Mary P. Walker ${ }^{4}$ \\ 1. Department of Oral Pathology, Medicine and Radiology, UMKC School of Dentistry, University of Missouri Kansas City, \\ USA. 2. Department of Periodontics, UMKC School of Dentistry, University of Missouri Kansas City, USA. 3. Department of \\ Biomedical and Health Informatics, UMKC School of Medicine, University of Missouri Kansas City, USA. 4. Departments of \\ Oral Biology \& Restorative Dentistry, UMKC School of Dentistry, University of Missouri Kansas City, USA.
}

Correspondence: Vandana Kumar. Address: 650 E 25th Street, Kansas City, MO 64108, USA. Email:

kumarva@umkc.edu.

Received: J une 11,2012

Accepted: January 3, 2013

Online Published: February 21, 2013

DOI : $10.5430 / j b g c . v 3 n 2 p 7$

URL: http://dx.doi.org/10.5430/jbgc.v3n2p7

\begin{abstract}
Objective: The utilization of cone beam computed tomographic imaging for oral implants has increased enormously for precise determination of anatomic dimensions. However, the impact of reorientation of data that influences the constructed panoramic view and thus the measurements on generated cross sectional views has not been explored. This study is undertaken to explore if differences exist in the implant height and width measurement when the whole data is reoriented from the standard manufacturer's setting to an aligned protocol (perpendicular to the implant (XYZ) settings).
\end{abstract}

Material and Methods: Two different orientation protocols were set up, standard and aligned or perpendicular setting (XYZ), and implant height and width measurements derived from these were compared to the original known measurements.

Results: The range of differences between actual dimensions and measurements obtained using each orientation method using McNemar's Change test in the four accuracy categories (exact, $+0.20,+0.25$, and +0.50 ) showed the aligned orientation produced larger proportion of width measurements between +0.25 and +0.50 compared to standard for width measures; however, these differences were not statistically significant. Implant length measurements varied widely and this variability was irrespective of orientation method.

Conclusions: The aligned/perpendicular (XYZ) protocol produces implant width measurements more accurate than length when compared to the standard protocol.

\section{Key words}

Implants, Cone beam CT, Multiplanar reconstruction

\section{I ntroduction}

The use of dental implants has become increasingly popular in dental treatment planning. Concomitantly, specialized radiographic imaging techniques have become more available for the preoperative planning of oral implant placement. Many clinical situations require the use of these advanced cross-sectional three-dimensional (3D) imaging techniques for optimal implant placement ${ }^{[1-3]}$. Cross-sectional information can be acquired with conventional medical computed 
tomography (CT) ${ }^{[4]}$. Despite the usefulness of medical CT in implant imaging ${ }^{[7-9]}$, the high cost, limited availability, and relatively high radiation exposure make its routine use impractical ${ }^{[5-9]}$. Cone Beam Computed Tomography (CBCT) is a

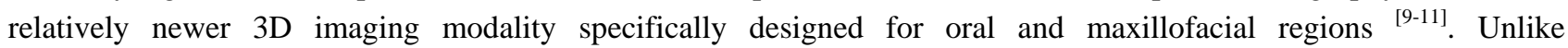
two-dimensional (2D) conventional radiographs, images obtained from CBCT scans are free of geometric distortion and superimposition ${ }^{[12,13]}$. Previous studies have established both the accuracy of linear measurements on 3D surfacerendered images and 2D tomographic slices generated from CBCT data ${ }^{[5,19-21]}$ as well as the utility in determining available bone height and width before implant selection ${ }^{[14-17]}$.

Once volumetric data are acquired from a CBCT machine, all slices are reconstructed and are presented to the clinician in three orthogonal planes (axial, sagittal and coronal) for viewing. The clinician has the ability to reorient the whole captured data set ${ }^{[18,19]}$. In this manner, patients' anatomic features can be realigned.

Reorientation of the whole data influences the constructed and reformatted panoramic view, and the various cross sections displayed. Though some clinicians and radiologists reorient the data for assessing bone height and width for implant purposes, the question persists "does orientation of the volume affect calculation of the implant dimensions that are chosen for the site?” Although the impact of CBCT imaging in preoperative implant planning has previously been investigated $^{[11,17,20-29]}$, the impact of reorientation of data on assessment of implant height and width measurement has not yet been explored. Since data reorientation influences the constructed reformatted panoramic view and various cross-sectional views displayed, this study was undertaken to explore if differences exist in the assessment of implant height and width measurement when the whole data is reoriented from the conventional manufacturers setting to aligned protocol settings in order to map the reformatted panoramic and cross-sectional views. The objective was to compare the accuracy of different multi-projection reconstructions (MPRs) in determining implant sizes in clinical practices. It was hypothesized that geometrical distortions caused by a specific multiplanar reconstruction (MPR) affect all visualized structures (bone, teeth, soft tissues) and therefore, could impact the measurements of osseous dimensions at the time of implant treatment planning. It was hypothesized that aligned protocol settings for the region of interest would give more accurate measurements than the standard manufacturer's protocol.

\section{Material and methods}

Seventeen subjects (9 males and 8 females, 35-50 years old) who wanted to have implants placed in right or left or both the maxillary canine sites, were selected for this study. Total of thirty-one implants were placed in these patients and high resolution CBCT scans of the implant sites were obtained. These scans were acquired as part of a clinical study on implant loading conducted by the Graduate Periodontics Department at the UMKC School of Dentistry with approval from the UMKC Adult Health Science's IRB. The scans were done using an I-CAT machine (Imaging Sciences International, Hatfield, PA) at $120 \mathrm{kVp}, 3 \mathrm{~mA}$, and $0.20 \mathrm{~mm}$ voxel size. Four implant sites showed metal artifacts on the scans, therefore, those were discarded. CBCT scans on remaining twenty-seven implant sites comprised a convenience sample for this study.

All CBCT scans were taken using the standard manufacturer I-CAT protocol. Once the high resolution scan of the patient was completed, the primary reconstruction started automatically by the software. The main display appeared on the screen showing axial, coronal and sagittal views of the skull through midline; the screen was referred as MPR (multi-projection reconstruction). Using this MPR data, a standard and an aligned protocol was performed as described below using the I-CAT native software.

\subsection{Standard viewing protocol}

The original orientation of the patient was maintained on the MPR display as shown in Figure 1. The slice in the axial view where the coronal third of roots for most of the teeth were visible was selected for mapping the occlusal arch to reconstruct the panoramic view. The occlusal arch was mapped by pointing, clicking and dragging the mouse around the arch in the 
axial view. The location of the implant at the two proximal ends of the implant was mapped through this method (see Figure 2). The slice that represented the mid-tomographic slice of the implant and gave the closest representation of the implants diameter and positioning relative to buccal and palatal buccal cortical plates was selected and saved as "single projection” in tagged image file format (TIFF, Adobe Systems Inc., 345 Park Ave., San Jose, CA 95110) for subsequent measurements using a specific imaging software program (Adobe Photoshop CS2).

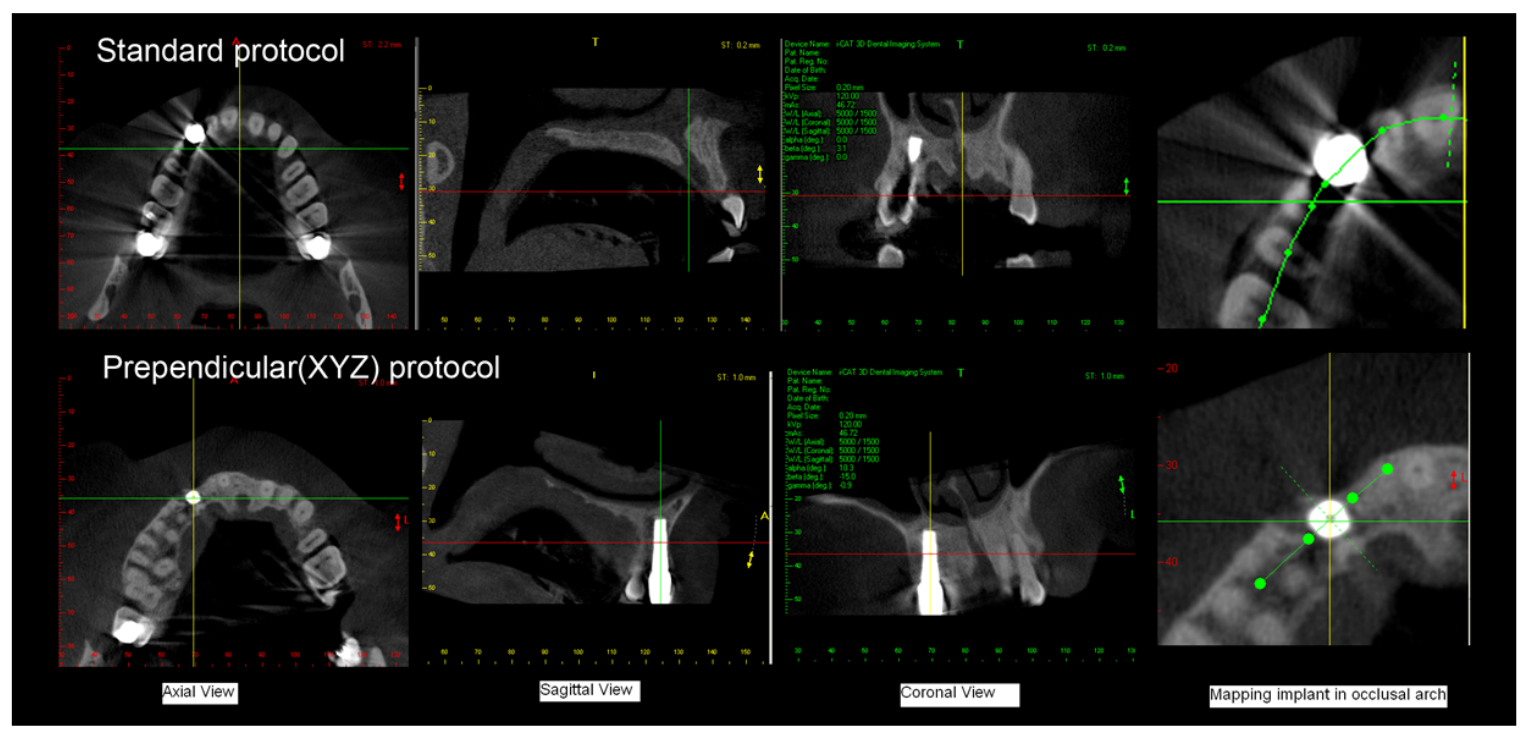

Figure 1. Comparison of standard and aligned (perpendicular XYZ) orientation protocol. For standard protocol, the original orientation of the implant maintained in the axial, sagittal and coronal views and implant was mapped in the occlusal arch to reconstruct panoramic view and cross-sectional views. For aligned (perpendicular XYZ) protocol, implant was located in the axial view, reoriented parallel to mid-sagittal axis in sagittal and coronal views and then mapped in occlusal arch to generate panoramic view and cross-sectional views.

Figure 2. Mapping of occlusal arch in axial view to generate and select the mid tomographic slice

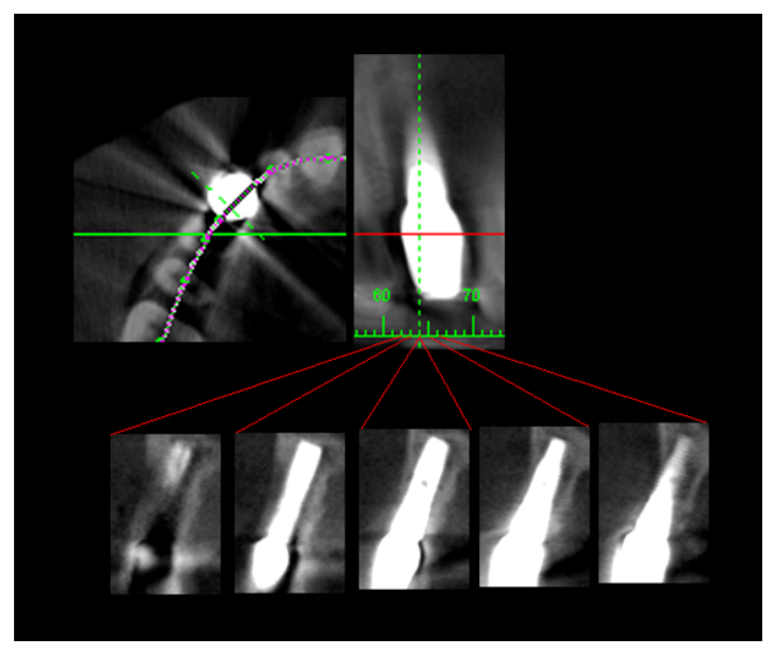
for standard protocol

\subsection{Aligned protocol (Perpendicular XYZ Protocol)}

For the perpendicular XYZ protocol or aligned protocol setting, the implant was located on the axial view. In the sagittal view, the volumetric data were reoriented until the implant was parallel to the mid-sagittal axis. Next, the coronal view was 
adjusted to orient the implant parallel to the mid-sagittal axis. Visualized in MPR view, the image was then lined up with the visible dot representing the internal void of implant fixture parallel to mid-sagittal plane. The whole volumetric data was thus reoriented to the XYZ axis. The occlusal arch was then mapped by drawing an arch line bisecting the internal void (see Figure 1). Reformatted panoramic and cross-sectional views of the implant were also created. The midtomographic slice identified by the internal void was selected and saved as a TIFF file for subsequent measurements using a specific imaging software program (Adobe Photoshop CS2) (see Figure 3).

Figure 3. Mapping of occlusal arch in axial view to generate and select the mid tomographic slice for aligned protocol

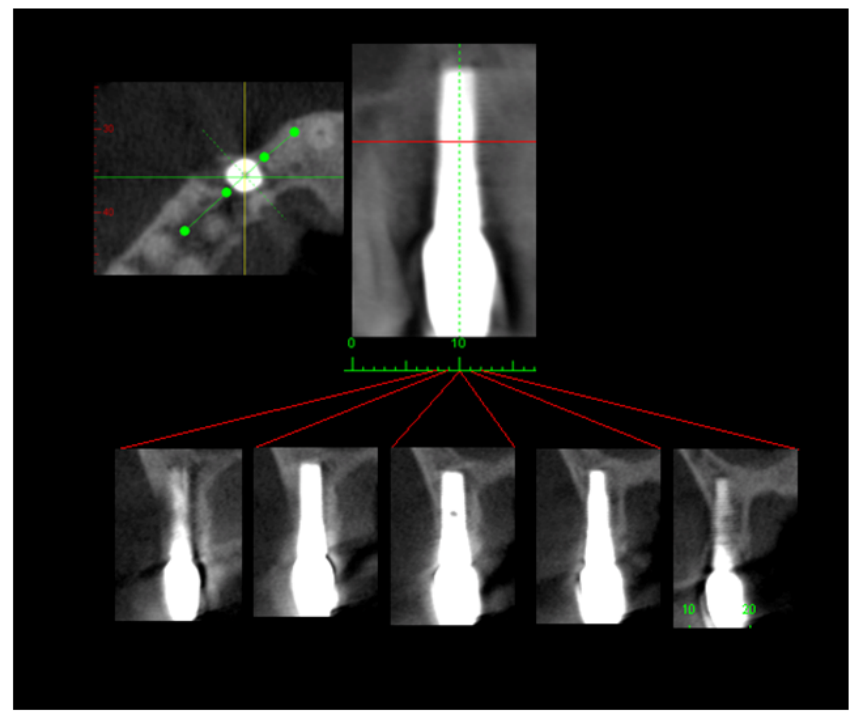

Since the saved TIFF file of mid tomographic slice was very small in size, each image was magnified 200 times to improve accuracy of measurement. The calibration tool provided in Adobe Photoshop was used to set each image size to $73.49 \mathrm{~mm}$ in width and $66.04 \mathrm{~mm}$ in height with resolution of 300 pixels/inch. The numeric grid captured from the I-Cat native software along with every cross-sectional image was matched with Adobe Photoshop measuring tool to assure proper distance measurement for each calibrated image. The I-Cat native software was not used for the measurement purposes due to concerns with reproducibility of measurement. Additionally, this method provided the opportunity to have raters measure images in a randomized order.

To assess inter- and intra- rater reliability, the two board-certified and calibrated oral maxillofacial radiologists independently obtained length and width measurements on each implant image. Two weeks later, the same examiners viewed scans collaboratively and obtained single, agreed upon length and width measurement for each implant. Intra-rater agreement was obtained between the initial independently obtained measure and the agreed upon measures two weeks later. Inter-rater reliability was obtained between the two initial, independently obtained measures.

Implant lengths were measured in millimeters ( $\mathrm{mm}$ ) from the reverse platform (e.g., the notch) to the apex of the implant. Implant width was measured in mm between mesial and distal notches (defining the reverse platform) located at the outer edges of the implant. The difference in implant length and width measurements obtained from each of the two orientations methods (Standard and Aligned) were then computed by subtracting the actual implant length and width dimensions from the obtained measures, respectively. Statistical analyses were conducted to determine if the error measurements in length and width for the two orientation protocols were different using paired $t$-tests. To explore the accuracy of measurements between actual implant dimensions and measures obtained under the two imaging orientation methods, measurement differences (in $\mathrm{mm}$ ) of twenty-seven implants were dichotomized into four "accuracy" categories: Absolute $(<0.01)$; Relative A (+0.20); Relative B ( $+0.25 \mathrm{~mm})$; and Relative C $(+0.50 \mathrm{~mm})$. The frequency of implants (the number of implants out of twenty-seven implants) in each “accuracy” category was compared using a one-tailed McNemar's Change 
Test. As this was an exploratory attempt to capture differences in accuracy of imaging modalities on a relatively small sample of subjects with pre-existing CBCT images we were only interested in whether the aligned protocol was more accurate than the standard protocol; therefore utilized a one-tailed test. Additionally, as type II error was a greater concern than type I error in the statistical analysis the decision was made, a priori, to use a critical value of alpha of 0.05 for each statistical comparison rather than use a Bonferroni approach which would greatly reduce power. McNemar's Change Test was used as it assumes a lack of independence among measures.

\section{Results}

Intraclass correlation coefficients (ICC) were computed to assess reliability for width and length measurements. ICC ratios for the two examiners ranged from 0.986 to 0.993 and 0.825 to 0.904 respectively. For inter-rater reliability of width and length measures, ICC’s were ranged from 0.83 to 0.99 , respectively.

The range of differences from actual measurement for implants of various dimensions for both the standard and aligned protocols are shown in Table 1. The mean (SD) and median (IQ) errors for the two orientation techniques for length and width are displayed in Table 2. Difference in mean error from gold standard for the two orientation techniques were not statistically different for implant length ( $t=-.049, p=.961)$ nor width $(t=-.037, p=.971)$. The average mean (S.D.) error for length for standard and aligned protocols were 0.60 (1.04) and 0.64 (1.08) mms, respectively. A similar trend in mean error was observed for width measures; however, variance estimates for aligned were somewhat smaller than that observed for standard (0.34 versus 0.59$)$ respectively.

Table 1. Showing actual length and width of implants and the range of differences from actual measurement for both the standard and aligned protocols

\begin{tabular}{|c|c|c|c|c|c|}
\hline \multirow{2}{*}{ Actual Width / Length } & \multirow{3}{*}{ No. of Implants } & \multicolumn{4}{|c|}{ Range of difference from actual measurement as function of implant size } \\
\hline & & \multicolumn{2}{|l|}{ Standard Protocol } & \multicolumn{2}{|c|}{ Aligned Protocol } \\
\hline Width / Length & & Width (mm) & Length (mm) & Width (mm) & Length (mm) \\
\hline $5 \mathrm{~mm} / 11 \mathrm{~mm}$ & 4 & -0.20 to 0.10 & 0.50 to 0.90 & -0.60 to 0.10 & 0.10 to 1.0 \\
\hline $3.5 \mathrm{~mm} / 13 \mathrm{~mm}$ & 3 & -0.60 to -0.40 & -0.10 to 0.30 & -0.40 to 0.90 & 0.10 to 0.40 \\
\hline $5 \mathrm{~mm} / 13 \mathrm{~mm}$ & 6 & -0.40 to 0.90 & -1.90 to 1.20 & -0.50 to 0.30 & -1.80 to 0.40 \\
\hline $3.5 \mathrm{~mm} / 15 \mathrm{~mm}$ & 1 & -0.80 & 0.40 & -0.50 & 0.10 \\
\hline $4.0 \mathrm{~mm} / 15 \mathrm{~mm}$ & 3 & -1.70 to 0.10 & 0.50 to 0.90 & -1.0 to 0.10 & 0.30 to 0.60 \\
\hline $4.5 \mathrm{~mm} / 15 \mathrm{~mm}$ & 3 & -1.30 to -0.80 & -0.40 to 3.0 & -1.0 to 0.10 & 0.20 to 3.80 \\
\hline $5 \mathrm{~mm} / 15 \mathrm{~mm}$ & 4 & -0.30 to 0.30 & 0.80 to 4.0 & -0.20 to 0 & 0.60 to 3.90 \\
\hline $4 \mathrm{~mm} / 17 \mathrm{~mm}$ & 3 & -0.40 to 0.10 & 0.30 to 0.70 & -0.30 to 0.10 & 0.40 to 0.80 \\
\hline
\end{tabular}

Table 2. Descriptive statistics for errors in implant length and width measures obtained by standard and aligned orientation protocols

\begin{tabular}{llll}
\hline Item & Mean Error (SD) & Median (IQ) & Range of Errors \\
\hline $\begin{array}{l}\text { Standard Protocol } \\
\quad \text { Length }\end{array}$ & $0.60(1.04)$ & $0.60(0.20,0.80)$ & -1.9 to 4.0 \\
$\quad$ Width & $-0.23(0.59)$ & $-0.20(-0.60,0.10)$ & -1.7 to 0.9 \\
$\begin{array}{l}\text { Aligned Protocol } \\
\quad \text { Length }\end{array}$ & $0.64(1.08)$ & $0.40(0.20,0.80)$ & -1.8 to 3.9 \\
$\quad$ Width & $-0.23(0.34)$ & $-0.20(-0.40,0)$ & -1.0 to 0.3 \\
\hline
\end{tabular}

When measurements of twenty-seven implants were categorized into categories using the pre-established standards of absolute agreement, $+0.20 \mathrm{~mm},+0.25 \mathrm{~mm}$, and $+0.50 \mathrm{~mm}$ (see Table 3 ) a slightly different pattern emerged. With the exception of absolute accuracy for length, results showed the aligned protocol orientation method produced a higher proportion of implants in each acceptability category compared to standard orientation. Exact reproduction of implant Published by Sciedu Press 
width dimensions and accuracy within the $+0.20 \mathrm{~mm}$ range were statistically greater for the aligned protocol orientation compared to standard orientation. Twenty-three percent of width measurements (6 of 26) were exactly replicated by examiners using the aligned protocol orientation compared to $0 \%$ for standard protocol $(p=0.031)$. For accuracy within the range of $+0.20 \mathrm{~mm}, 34.6 \%$ of $\mathrm{XYZ}$ width measurements were determined to be accurate compared to $15.4 \%$ with standard. The trend for aligned protocol having a larger proportion of accurate width measurements in the +0.25 and +0.50 categories compared to standard persisted; however, these differences were not statistically significant.

Table 3. Percent agreement with actual length and width implant measurements using four standards for error acceptability

\begin{tabular}{lllll}
\hline Measurements & Exact N (\%) & Within $\pm \mathbf{0 . 2 0 N}(\%)$ & Within $\pm \mathbf{0 . 2 5} \mathbf{N}(\%)$ & Within $\pm \mathbf{0 . 5 0} \mathbf{N}(\%)$ \\
\hline Implant Length & & & & \\
Standard & $2(7.6 \%)$ & $5(19.2 \%)$ & $5(19.2 \%)$ & $12(46.2 \%)$ \\
Aligned & $1(3.8 \%)$ & $7(26.9 \%)$ & $7(26.9 \%)$ & $15(57.7 \%)$ \\
Implant Width & & & \\
Standard & $0(0 \%)$ & $4(15.4 \%)$ & $11(42.3 \%)$ & $17(65.4 \%)$ \\
Aligned & $6(23.1 \%)^{*}$ & $9(34.6 \%)^{* *}$ & $15(57.7 \%)$ & $22(84.6 \%)$ \\
\hline
\end{tabular}

*Statistically significant ( $\mathrm{p}=.031)$; ** Statistically significant ( $\mathrm{p}=.062) ; \mathrm{N}=$ number of implants out of twenty-seven implants in each "accuracy" category

\section{Discussion}

The results partially confirmed our hypothesis that the reorientation of data would produce more accurate measurements of implant dimensions than the standard orientation. To our knowledge, this is the first study to report on using high resolution CBCT images to observe the amount of error in implant length and width measurements for the two different orientations protocols. Results showed that the standard protocol, irrespective of operational definition (absolute, +0.20 , +0.25 , and +0.50 ) produced less accurate width and length dimensions than the reoriented images. While length measurements were slightly less accurate than width measurements, they were slightly better than those obtained using the standard protocol although the differences were not significant.

A possible explanation for these differences could be related to basic cone beam volume reconstruction and image formation as well as the shape of the implant. Cone beam volume is captured during a circular scan of the subject that enables reconstruction of the data using a Feldkamp-based cone beam reconstruction algorithm ${ }^{\text {[30-32] }}$. CBCT volume is composed of voxels, which are purported to be isometrically proportioned ${ }^{[18,19]}$ in the reconstructed CBCT scan volume; however, data remain to be subjectively reoriented in MPR view of the subject. Although no specific research has detailed distortion of reformatted images of CBCT and accuracy of measurements, it is possible that geometric distortion can occur when arbitrary planes are used to view the isotropic voxels of a volumetric scan. When the manufacturer's software reformats acquired voxel data into a new projection, the voxels are reprojected into the same size output data grid. The smallest dimension that can be used in the original voxel data and a rigidly reformatted image (without sub sampling methods) is indeed the dimension of the isotropic voxel. While it is possible to calculate distances based upon edge lengths of the acquired isotropic voxels, this may be masked by the effects of the reformatting algorithms used in forming the projection images of the implants. With the axial, coronal and sagittal reformatting angles, it is possible (in principle) to pre-calculate the distances in the reformatted images. However, the uncertainty of distance measurements in each reprojected direction depends on the reformatting algorithms used in the manufacturer-supplied reprojection software which is generally not known to the clinician.

In addition, the cylindrical shape of implant is another factor that could influence length and width measurements. Any change in anterior-posterior and frontal/coronal axis of the implant image could affect its reformatted long axis, creating a longer image. In contrast, the circular diameter of the implant remains unaffected by this reformatting. 
Use of the aligned protocol could positively impact clinical decisions regarding implant diameter selection, since it is crucial to have a minimum of $2.0 \mathrm{~mm}$ of bone apical and proximal to the implant and critical anatomic structures ${ }^{\text {[33] }}$. Also, assessment of long term osseous changes that may indicate success or failure of implant may be more accurately evaluated using this reorientation protocol. Clearly longitudinal studies are needed to validate whether this protocol would improve diagnostic accuracy of implant success or failure.

An important drawback in this study is that only one CBCT unit has been employed with specific beam energy and field of view (FoV) - voxel size settings. Different CBCT systems could have different measurement results because of differences in detector type, scanning and reconstruction parameters and artifact levels. A large FoV may provide less accurate reconstructions than a smaller FoV because of the greater beam angulation in the superior and inferior volume area, and reduced contrast to noise ratio. The FoVs in this study had specific voxel sizes, which were not adjustable. Thus it was difficult to evaluate the influence of this parameter individually. Also, the voxel size itself has an important influence on the noise in the orthogonal slices: the smaller the voxel size, the greater the noise, but the better the spatial resolution. It is therefore crucial in the future studies to investigate all parameters and their influence on the reconstruction accuracy ${ }^{\text {[34-37] }}$. Other factors that lead to potential measurement errors are streak and star artifacts in the reconstructed CT/ CBCT images from metal implants ${ }^{[38-40]}$. In our sample, the images were prescreened to include scans which did not demonstrate large metal artifacts. Only two observers were used in the study. Impact of increasing the number of observers on accuracy of results can be investigated in future studies.

\section{Conclusions}

While many experts using implant planning software might reorient all reconstructions perpendicular to the implant, this study provides evidence that perpendicular orientation to the region of interest provides more accurate width measurements and therefore, could be used effectively for determining implant sizes in clinical practices. The reproducibility of aligned protocol and its advantage in assessing long-term pathological bone lesions and bisphosphonate related lesions using a radiographic marker could be explored in future studies.

\section{References}

[1] Van Assche N, van Steenberghe D, Guerrero ME, et al. Accuracy of implant placement based on pre-surgical planning of threedimensional cone-beam images: a pilot study. J Clin Periodontol. 2007; 34: 816-821. PMid:17716317 http://dx.doi.org/10.1111/j.1600-051X.2007.01110.x

[2] Tardieu PB, Vrielinck L, Escolano E, Henne M, Tardieu AL. Computer-assisted implant placement: scan template, simplant, surgiguide, and SAFE system. Int J Periodontics Restorative Dent. 2007; 27: 141-149. PMid:17514886

[3] Sato S, Arai Y, Shinoda K, Ito K. Clinical application of a new cone-beam computerized tomography system to assess multiple two-dimensional images for the preoperative treatment planning of maxillary implants: case reports. Quintessence Int. 2004; 35: 525-528. PMid:15259967

[4] Garg AK, Vicari A. Radiographic modalities for diagnosis and treatment planning in implant dentistry. Implant Soc. $1995 ;$ 5: 7-11. PMid:9571835

[5] Chau AC, Fung K. Comparison of radiation dose for implant imaging using conventional spiral tomography, computed tomography, and cone-beam computed tomography. Oral surgery, oral medicine, oral pathology, oral radiology, and endodontics. 2009; 107: 559-565. PMid:19168378 http://dx.doi.org/10.1016/j.tripleo.2008.11.009

[6] Okano T, Harata Y, Sugihara Y, et al. Absorbed and effective doses from cone beam volumetric imaging for implant planning. Dento maxillo facial radiology. 2009; 38: 79-85. PMid:19176649 http://dx.doi.org/10.1259/dmfr/14769929

[7] Roberts JA, Drage NA, Davies J, Thomas DW. Effective dose from cone beam CT examinations in dentistry. The British journal of radiology. 2009; 82: 35-40. PMid:18852212 http://dx.doi.org/10.1259/bjr/31419627

[8] Silva MA, Wolf U, Heinicke F, Bumann A, Visser H, Hirsch E. Cone-beam computed tomography for routine orthodontic treatment planning: a radiation dose evaluation. Am J Orthod Dentofacial Orthop. 2008; 133: 640 e641-645. 
[9] Monsour PA, Dudhia R. Implant radiography and radiology. Australian dental journal. 2008; 53 Suppl 1: S11-25. PMid:18498579 http://dx.doi.org/10.1111/j.1834-7819.2008.00037.x

[10] Lagravere MO, Carey J, Toogood RW, Major PW. Three-dimensional accuracy of measurements made with software on conebeam computed tomography images. Am J Orthod Dentofacial Orthop. 2008; 134: 112-116. PMid:18617110 http://dx.doi.org/10.1016/j.ajodo.2006.08.024

[11] Dreiseidler T, Mischkowski RA, Neugebauer J, Ritter L, Zoller JE. Comparison of cone-beam imaging with orthopantomography and computerized tomography for assessment in presurgical implant dentistry. The International journal of oral \& maxillofacial implants. 2009; 24: 216-225. PMid:19492636

[12] Estrela C, Bueno MR, Leles CR, Azevedo B, Azevedo JR. Accuracy of cone beam computed tomography and panoramic and periapical radiography for detection of apical periodontitis. Journal of endodontics. 2008; 34: 273-279. PMid:18291274 http://dx.doi.org/10.1016/j.joen.2007.11.023

[13] Miracle AC, Mukherji SK. Conebeam CT of the head and neck, part 1: physical principles. Ajnr. 2009; 30: 1088-1095. PMid:19439484 http://dx.doi.org/10.3174/ajnr.A1653

[14] Ito K, Gomi Y, Sato S, Arai Y, Shinoda K. Clinical application of a new compact CT system to assess 3-D images for the preoperative treatment planning of implants in the posterior mandible A case report. Clinical oral implants research. 2001; 12: 539-542. PMid:11564116 http://dx.doi.org/10.1034/j.1600-0501.2001.120516.x

[15] Veyre-Goulet S, Fortin T, Thierry A. Accuracy of linear measurement provided by cone beam computed tomography to assess bone quantity in the posterior maxilla: a human cadaver study. Clinical implant dentistry and related research. 2008; 10: 226-230. PMid:18384410

[16] Garg AK. Dental implant imaging: TeraRecon's Dental 3D Cone Beam Computed Tomography System. Dental implantology update. 2007; 18: 41-45. PMid:17682685

[17] Rugani P, Kirnbauer B, Arnetzl GV, Jakse N. Cone beam computerized tomography: basics for digital planning in oral surgery and implantology. International journal of computerized dentistry. 2009; 12: 131-145. PMid:19413269

[18] Araki K, Maki K, Seki K, et al. Characteristics of a newly developed dentomaxillofacial X-ray cone beam CT scanner (CB MercuRay): system configuration and physical properties. Dento maxillo facial radiology. 2004; 33: 51-59. PMid:15140823 http://dx.doi.org/10.1259/dmfr/54013049

[19] White SC. Cone-beam imaging in dentistry. Health physics. 2008; 95: 628-637. PMid:18849696 http://dx.doi.org/10.1097/01.HP.0000326340.81581.1a

[20] Hatcher DC, Dial C, Mayorga C. Cone beam CT for pre-surgical assessment of implant sites. Journal of the California Dental Association. 2003; 31: 825-833. PMid:14696834

[21] Loubele M, Guerrero ME, Jacobs R, Suetens P, van Steenberghe D. A comparison of jaw dimensional and quality assessments of bone characteristics with cone-beam CT, spiral tomography, and multi-slice spiral CT. The International journal of oral \& maxillofacial implants. 2007; 22: 446-454. PMid:17622012

[22] Loubele M, Maes F, Schutyser F, Marchal G, Jacobs R, Suetens P. Assessment of bone segmentation quality of cone-beam CT versus multislice spiral CT: a pilot study. Oral surgery, oral medicine, oral pathology, oral radiology, and endodontics. 2006; 102: 225-234. PMid:16876067 http://dx.doi.org/10.1016/j.tripleo.2005.10.039

[23] Peck JL, Sameshima GT, Miller A, Worth P, Hatcher DC. Mesiodistal root angulation using panoramic and cone beam CT. The Angle orthodontist. 2007; 77: 206-213. http://dx.doi.org/10.2319/0003-3219(2007)077[0206:MRAUPA]2.0.CO;2

[24] Naitoh M, Hiraiwa Y, Aimiya H, Ariji E. Observation of bifid mandibular canal using cone-beam computerized tomography. The International journal of oral \& maxillofacial implants. 2009; 24: 155-159.

[25] Naitoh M, Nakahara K, Suenaga Y, Gotoh K, Kondo S, Ariji E. Comparison between cone-beam and multislice computed tomography depicting mandibular neurovascular canal structures. Oral surgery, oral medicine, oral pathology, oral radiology, and endodontics. 109: e25-31. PMid:20123365 http://dx.doi.org/10.1016/j.tripleo.2009.08.027

[26] Dreiseidler T, Neugebauer J, Ritter L, et al. Accuracy of a newly developed integrated system for dental implant planning. Clinical oral implants research. 2009; 20: 1191-1199. PMid:19681962 http://dx.doi.org/10.1111/j.1600-0501.2009.01764.x

[27] Bamgbose BO, Adeyemo WL, Ladeinde AL, Ogunlewe MO. Conebeam computed tomography (CBCT): the new vista in oral and maxillofacial imaging. Nigerian quarterly journal of hospital medicine. 2008; 18: 32-35. PMid:19062469

[28] Angelopoulos C, Thomas SL, Hechler S, Parissis N, Hlavacek M. Comparison between digital panoramic radiography and cone-beam computed tomography for the identification of the mandibular canal as part of presurgical dental implant assessment. $\mathrm{J}$ Oral Maxillofac Surg. 2008; 66: 2130-2135. PMid:18848113 http://dx.doi.org/10.1016/j.joms.2008.06.021

[29] Howerton WB, Jr., Mora MA. Advancements in digital imaging: what is new and on the horizon? Journal of the American Dental Association (1939). 2008; 139 Suppl: 20S-24S. 
[30] Hein I, Taguchi K, Silver MD, Kazama M, Mori I. Feldkamp-based cone-beam reconstruction for gantry-tilted helical multislice CT. Medical physics. 2003; 30: 3233-3242. PMid:14713090 http://dx.doi.org/10.1118/1.1625443

[31] Mori S, Endo M, Komatsu S, Kandatsu S, Yashiro T, Baba M. A combination-weighted Feldkamp-based reconstruction algorithm for cone-beam CT. Physics in medicine and biology. 2006; 51: 3953-3965. PMid:16885617 http://dx.doi.org/10.1088/0031-9155/51/16/005

[32] Mori S, Endo M, Kondo C, Tanada S. Physical evaluation of the weighted Feldkamp algorithms applied to the 256-detector row CT scanner for volumetric cine imaging. Academic radiology. 2006; 13: 701-712. PMid:16679272 http://dx.doi.org/10.1016/j.acra.2006.03.002

[33] Greenstein G, Tarnow D. The mental foramen and nerve: clinical and anatomical factors related to dental implant placement: a literature review. Journal of periodontology. 2006; 77: 1933-1943. PMid:17209776 http://dx.doi.org/10.1902/jop.2006.060197

[34] Hassan B, van der Stelt P, Sanderink G. Accuracy of three-dimensional measurements obtained from cone beam computed tomography surface-rendered images for cephalometric analysis: influence of patient scanning position. European journal of orthodontics. 2009; 31: 129-134. PMid:19106265 http://dx.doi.org/10.1093/ejo/cjn088

[35] Al-Rawi B, Hassan B, Vandenberge B, Jacobs R. Accuracy assessment of three-dimensional surface reconstructions of teeth from Cone Beam Computed Tomography scans. Journal of oral rehabilitation.

[36] Damstra J, Fourie Z, Huddleston Slater JJ, Ren Y. Accuracy of linear measurements from cone-beam computed tomographyderived surface models of different voxel sizes. Am J Orthod Dentofacial Orthop; 137: 16 e11-16; discussion 16-17.

[37] Seet KY, Barghi A, Yartsev S, Van Dyk J. The effects of field-of-view and patient size on CT numbers from cone-beam computed tomography. Physics in medicine and biology. 2009; 54: 6251-6262. PMid:19794246 http://dx.doi.org/10.1088/0031-9155/54/20/014

[38] Lemmens C, Faul D, Nuyts J. Suppression of metal artifacts in CT using a reconstruction procedure that combines MAP and projection completion. IEEE transactions on medical imaging. 2009; 28: 250-260. PMid:19188112 http://dx.doi.org/10.1109/TMI.2008.929103

[39] Wei J, Chen L, Sandison GA, Liang Y, Xu LX. X-ray CT high-density artefact suppression in the presence of bones. Physics in medicine and biology. 2004; 49: 5407-5418. PMid:15724532 http://dx.doi.org/10.1088/0031-9155/49/24/001

[40] Zhang Y, Zhang L, Zhu XR, Lee AK, Chambers M, Dong L. Reducing metal artifacts in cone-beam CT images by preprocessing projection data. International journal of radiation oncology, biology, physics. 2007; 67: 924-932. PMid:17161556 http://dx.doi.org/10.1016/j.ijrobp.2006.09.045 